\title{
In vitro surgical and non-surgical air-polishing efficacy for implant surface decontamination in three different defect configurations
}

\author{
Vivian Tuchscheerer ${ }^{1} \cdot$ Peter Eickholz ${ }^{2} \cdot$ Bettina Dannewitz $^{2,3} \cdot$ Christoph Ratka $^{4} \cdot$ Otto Zuhr ${ }^{2,5} \cdot$ Hari Petsos $^{2,6}$ (D)
}

Received: 3 June 2020 / Accepted: 24 July 2020 / Published online: 19 August 2020

(C) The Author(s) 2020

\begin{abstract}
Objectives Evaluation of surgical and non-surgical air-polishing in vitro efficacy for implant surface decontamination. Material and methods One hundred eighty implants were distributed to three differently angulated bone defect models $\left(30^{\circ}, 60^{\circ}\right.$, $90^{\circ}$ ). Biofilm was imitated using indelible red color. Sixty implants were used for each defect, 20 of which were air-polished with three different types of glycine air powder abrasion (GAPA1-3) combinations. Within 20 equally air-polished implants, a surgical and non-surgical (with/without mucosa mask) procedure were simulated. All implants were photographed to determine the uncleaned surface. Changes in surface morphology were assessed using scanning electron micrographs (SEM).

Results Cleaning efficacy did not show any significant differences between GAPA1-3 for surgical and non-surgical application. Within a cleaning method significant $(p<0.001)$ differences for GAPA2 between $30^{\circ}(11.77 \pm 2.73 \%)$ and $90^{\circ}(7.25 \pm 1.42 \%)$ in the non-surgical and $30^{\circ}(8.26 \pm 1.02 \%)$ and $60^{\circ}(5.02 \pm 0.84 \%)$ in the surgical simulation occurred. The surgical use of air-polishing $(6.68$ $\pm 1.66 \%$ ) was significantly superior $(p<0.001)$ to the non-surgical $(10.13 \pm 2.75 \%)$. SEM micrographs showed no surface damages after use of GAPA.

Conclusions Air-polishing is an efficient, surface protective method for surgical and non-surgical implant surface decontamination in this in vitro model. No method resulted in a complete cleaning of the implant surface.

Clinical relevance Air-polishing appears to be promising for implant surface decontamination regardless of the device.
\end{abstract}

Keywords Dental implants $\cdot$ Decontamination $\cdot$ Abrasion $\cdot$ Dental air $\cdot$ Peri-implantitis

\section{Introduction}

Hari Petsos and Otto Zuhr contributed equally to this work.

Hari Petsos

petsos@med.uni-frankfurt.de

Salzhausen, Germany

2 Department of Periodontology, Center for Dentistry and Oral Medicine (Carolinum), Johann Wolfgang Goethe-University Frankfurt/Main, Theodor-Stern-Kai 7, 60596 Frankfurt/ Main, Germany

3 Weilburg, Germany

4 Department of Prosthodontics, Center for Dentistry and Oral Medicine (Carolinum), Johann Wolfgang Goethe-University Frankfurt/Main, Theodor-Stern-Kai 7, 60596 Frankfurt/ Main, Germany

5 Munich, Germany

6 Soest, Germany
There is clear evidence that plaque is the primary etiological factor for the development of peri-implant mucositis or periimplantitis [1] as it was compiled at the 2017 classification workshop for periodontal and peri-implant diseases [2]. Thus, prevention and therapy of these diseases aims to disrupt the biofilm on the implant surface as a cause. In addition to an ineffective plaque control [3], there are other risk factors such as smoking [4], history of periodontitis [5, 6], and irregular maintenance $[7,8]$. Non-surgical treatment of peri-implant mucositis has turned out to be the method of choice [9-11], while in peri-implantitis non-surgical treatment alone is largely not effective $[1,9,12]$ due to the re-maturing of plaque. In contrast, the surgical intervention with direct insight to the defect, better accessibility, and the possibility to avoid recolonization due to resective or regenerative procedures has proven to be superior $[13,14]$. Nevertheless, the implant geometry with its micro- and/or macro-threads and the rough 
surface morphology with an individual surface roughness remain difficult to clean in daily routine even with good insight and improved accessibility $[15,16]$. Rigid instruments such as curettes and (ultra)sonic scalers with steel tips have recently failed to convince in both non-surgical and surgical simulated in vitro experiments [17-19]. Although these in vitro results seem clear, current clinical evidence does not show clear data for or against the use of these instruments [20]. Alternatives such as lasers and air-polishing systems partly offer beneficial results when used on complex implant surfaces [21, 22]. However, this benefit seems to be limited depending on defect morphology and extension [9, 20, 23]. Using the laser, this limitation additionally seems to be due to its rigid tip, which impairs the application of the laser beam, and the consequently poorer accessibility [24]. When using air-polishing, the powder particles have the advantage of being able to be reflected in the typically shaped peri-implant bone defects, which probably leads to a cleaning effect even in areas that are difficult to access $[17,25]$. The use of glycine-based powder, which is a human protein component, has the advantage of being absorbable and not remaining in a wound as a foreign body. On the other hand, scanning electron microscope (SEM) images have recently shown that glycine-based powder has a less abrasive effect on implant surfaces compared to sodium bicarbonate powder [26-28].

The use of air-polishing with glycine powder has proven to be superior in both the surgical [17, 19] and the non-surgical [18] in vitro approach compared to steel curettes and (ultra)sonic scaler with steel tips. Consequently, this study aims to compare different air-polishing methods in both approaches for three defect configurations $\left[30^{\circ}, 60^{\circ}\right.$ (intraosseous defects), $90^{\circ}$ (supraosseous defect)] in order (i) to expand the available data on efficacy of surgical and non-surgical air-polishing application and (ii) to compare the efficacy of different air-polishing devices in both, a surgical and non-surgical in vitro simulation. The null hypothesis was that all air-polishing device combinations showed statistically different outcomes in terms of percentage of color remnants on the implant surface according to the type of approach and defect morphology and that different surface alterations resulted after cleaning. To the best of the authors' knowledge, no further in vitro investigation is known that compares the efficacy of different glycine-based air powder abrasion devices for implant surface decontamination.

\section{Materials and methods}

\section{Implant preparation and model}

The study was largely based on the set-up by Ronay et al. [18] and also follows approaches from Sahrmann et al. [19] and Keim et al. [17].
One hundred and eighty tissue-level implants with a subcrestal length of $12 \mathrm{~mm}$ and a diameter of $4.1 \mathrm{~mm}$ $\left(\right.$ OKTAGON $^{\circledR}$ Dental Implant System — made by Meisinger, DENTAL RATIO ${ }^{\circledR}$, Langenfeld, Germany) were dipped for $5 \mathrm{~s}$ into red color (Staedler permanent lumocolor, Nuremberg, Germany) and air-dried for $24 \mathrm{~h}$ to imitate a plaque-covered surface. All parts of the surface were completely and homogeneously covered. The implant consisted of a 2.3-mm machined surface in the supracrestal part and a rough sand-blasted and etched surface with a mean surface roughness of $1.69 \mu \mathrm{m}$ in the subcrestal part. The macrostructure of the rough implant surface was made of $0.35 \mathrm{~mm}$ high threads arranged at a distance of $1.25 \mathrm{~mm}$ from each other.

The in vitro defect model was computer-aided designed and manufactured in acrylic glass with $30^{\circ}$ and $60^{\circ}$ defect angulations as intraosseous defects and a $90^{\circ}$ defect angulation as supraosseous defect (Figs. 1 and 2). The implants in the intraosseous defect simulation were placed $12 \mathrm{~mm}$ (complete rough implant surface) into the models in order to simulate a supracrestal position of the machined surface. The defect depth in the intraosseous defects was $6 \mathrm{~mm}$. Therefore, the supraosseous defect simulation resulted in a supracrestal position of the machined and the rough implant surface [17-19]. Every implant was surrounded by acrylic glass in the apical $6 \mathrm{~mm}$ (Fig. 1). The defect models were uncovered to simulate the surgical/open approach and covered with an individually manufactured nontransparent mucosa mask (Adisil ${ }^{\circledR}$ rosé 1:1, Siladent, Goslar, Germany) in order to prevent visual control of the cleaning procedure for the non-surgical/covered approach simulation (Fig. 3) [18].

\section{Simulation procedure}

A total of 180 implants were examined. Each of the three different cleaning methods was tested on 20 of the 60 implants per defect angle. The 20 implants were again separated into 10 implants that were treated in a surgical approach and 10 implants that were treated in a non-surgical approach. Each of the three simulation models had a correspondingly individualized mucosal mask that was reused for all 30 implants that were cleaned in this model non-surgically. In the process, the following air powder abrasion and glycine powder type combinations (GAPA, glycine air powder abrasion) for surface decontamination were used (Fig. 3):

GAPA1: Air-Flow® Handy 2+ (EMS GmbH, Munich, Germany) with a PERIO-FLOW ${ }^{\circledR}$ handpiece (EMS) using glycine powder (3M $\mathrm{M}^{\mathrm{TM}}$ Clinpro $^{\mathrm{TM}}$ Glycine Prophy Powder, 3M Germany GmbH, Neuss, Germany) and an attached PERIO-FLOW ${ }^{\circledR}$ nozzle tip (EMS) as frequently studied combination [29-32].

GAPA2: Air-Flow® Handy 2+ (EMS) with a PERIOFLOW $^{\circledR}$ handpiece (EMS) using glycine powder 
Fig. 1 Lateral view of the three different defect angulations a $30^{\circ}$, b $60^{\circ}$, and c $90^{\circ}$ without mucosal mask
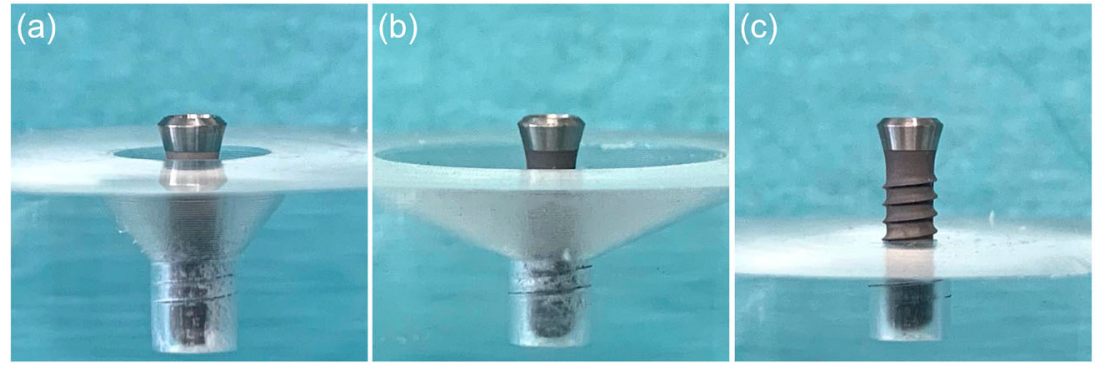

(AIRFLOW ${ }^{\circledR}$ PERIO, EMS) and an attached PERIOFLOW $^{\circledR}$ nozzle tip (EMS) as manufacturer combination GAPA3: Perio-Mate (NSK Europe GmbH, Eschborn, Germany) with glycine powder (Perio-Mate ${ }^{\mathrm{TM}}$ Powder, NSK) and attached Perio-Mate nozzle tip (NSK) using the medium ejection setting for powder and water spray volume as manufacturer combination.

Settings for the amount of water and powder emission were not freely selectable for GAPA1 and 2. Air pressure could not be adjusted on any of the selected devices. For each airpolishing device, combination settings were measured three times post-hoc with attached nozzle tip and then averaged: (1) water ejection [water was collected for $1 \mathrm{~min}$ and measured ( $\mathrm{ml} / \mathrm{min})],(2)$ powder emission rate [the chamber of the airpolishing device was filled to the maximum, this amount was weighed and after $1 \mathrm{~min}$ of use it was weighed again and the difference was calculated (g/min)], and (3) the drive airpressure [a multi-gauge was connected and read between the air-polishing device and the connection to the dental unit (bar)]. The nozzle tip for all combinations was used only once for every implant. All powder types had a mean particle size of $\sim 25 \mu \mathrm{m}$ and were water-soluble.

(a)
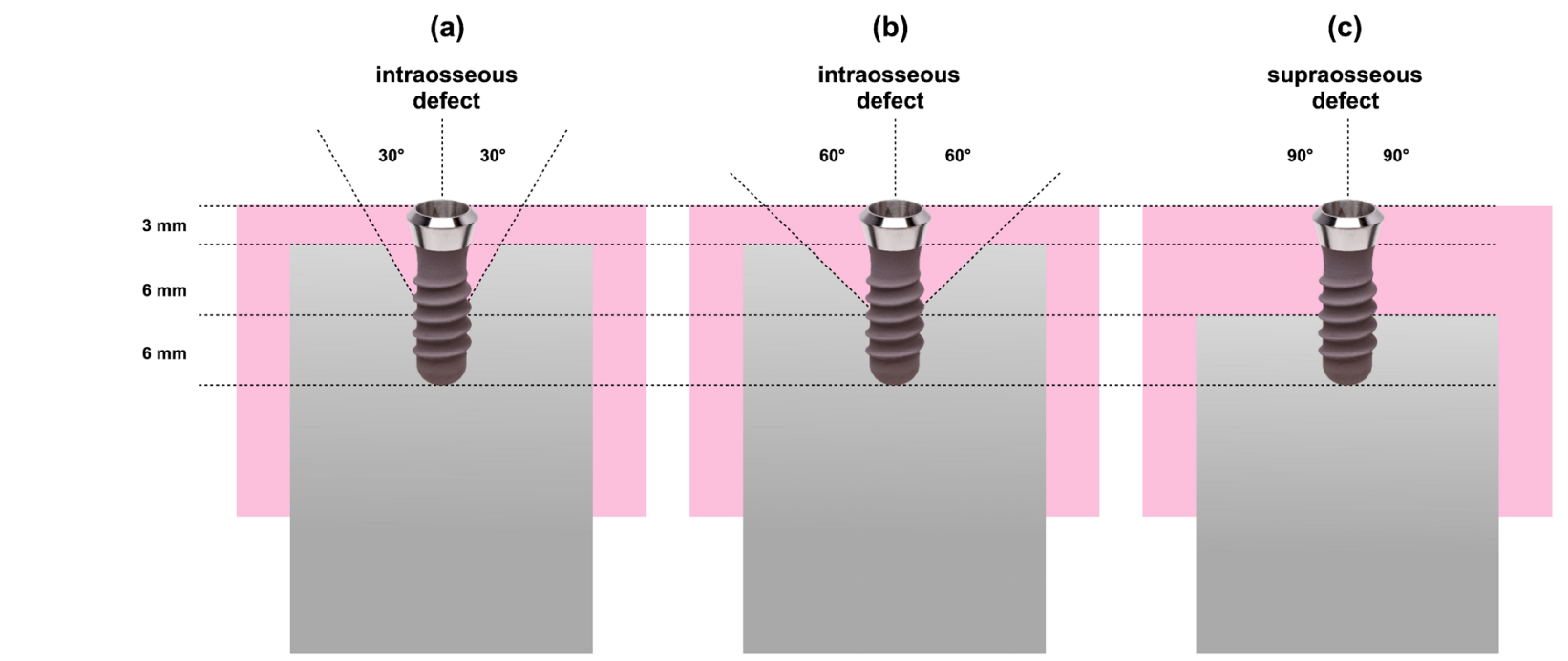

(b)

All implants were cleaned with or without mucosa mask for $2 \mathrm{~min}$ by the same operator (VT). Working distance and working angle were individually selected by the operator. After each instrumentation, the mucosa mask, if used, and the implant were removed. Dissolved color remnants were removed with a gentile air-water rinse for $10 \mathrm{~s}[17,19]$.

\section{Photo documentation and analysis}

Photo documentation was performed in accordance with Sahrmann et al. [19] and Keim et al. [17]. Implants were removed individually without surface contact from the model and fixed (Implant Driver, OKTAGON Dental Implant System) in an individually fabricated immovable holder. Afterwards, both sides $\left(180^{\circ}\right)$ of the implants were digitally photographed in a standardized manner [(Canon EOS 70D, Tokyo, Japan) $31.4 \mathrm{~cm}$ distance, ISO 100, aperture f/32, exposure time $1 / 250 \mathrm{~s}$ ) by the same examiner (VT) in an uniformly illuminated photo tent (proxistar, Kastl, Germany) with ring flash (Canon ring flash MR-14, Tokyo, Japan)] (Fig. 4) [17, 19].

All photos were analyzed (VT) using photo editing freeware (ImageJ 1.52a, U.S. National Institutes of Health,
Fig. 2 Drawings of the three different defect models a $30^{\circ}, \mathbf{b} 60^{\circ}$, and c $90^{\circ}$ with mucosal mask each with an exemplary inserted schematic draft of an untreated OKTAGON $4.1 \times 12$ mm $\left(\right.$ OKTAGON $^{\circledR}$ Dental Implant System - made by Meisinger, DENTAL RATIO ${ }^{\circledR}$, Langenfeld,
Germany) implant with $0.35 \mathrm{~mm}$ thread depth and $1.25 \mathrm{~mm}$ thread distance (macro-thread). A gingival thickness of $3 \mathrm{~mm}$ was simulated in the non-surgical approach 
Fig. 3 Use of both air-polishing devices (PERIO-FLOW ${ }^{\circledR}$ by EMS, Perio-Mate by NSK) with the respective nozzle tip supplied by the manufacturer is shown: a Perio-Mate with attached PerioMate nozzle (NSK) in a surgical and $\mathbf{b}$ non-surgical approach, $\mathbf{c}$ frontal, $\mathbf{d}$ lateral view of PerioMate nozzle tip (NSK) with two outlets ( $1 \mathrm{x}$ towards the front and $1 \mathrm{x}$ towards the apical direction); $\mathrm{e}$ PERIO-FLOW $^{\circledR}$ with attached PERIO-FLOW ${ }^{\circledR}$ nozzle tip (EMS) in a surgical and $\mathbf{f}$ nonsurgical approach, $\mathbf{g}$ frontal, and $\mathbf{h}$ lateral view of PERIO-FLOW ${ }^{\circledR}$ nozzle tip (EMS) with three outlets ( $1 \mathrm{x}$ towards the front and $2 \mathrm{x}$ opposite towards the side)
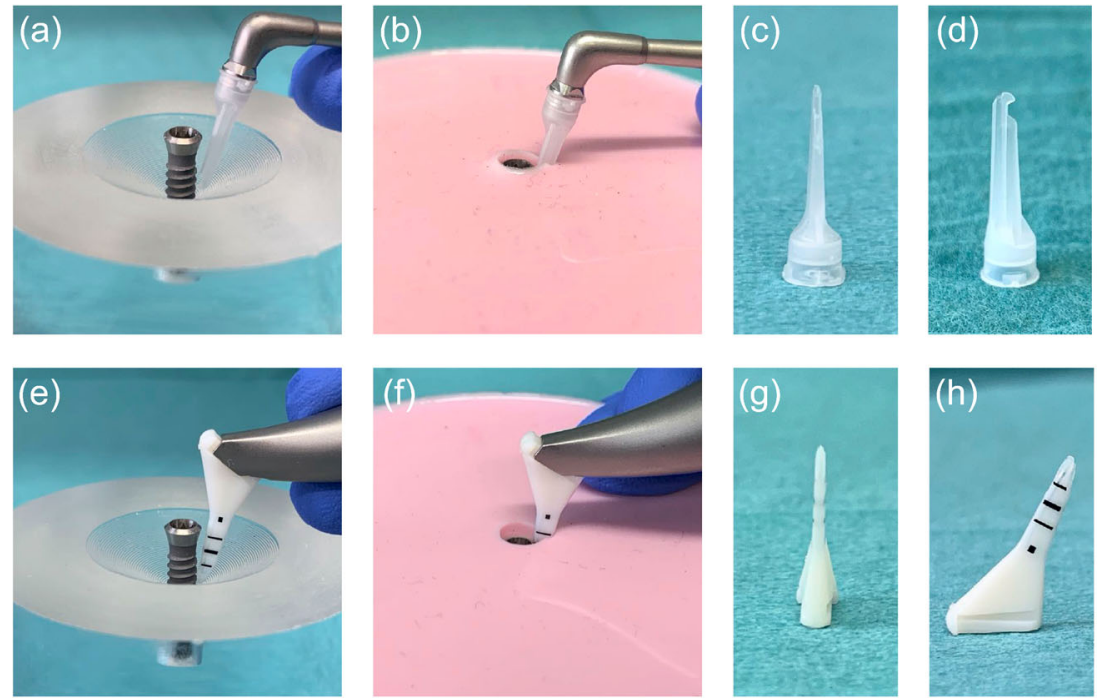

Bethesda, MD, USA; https://imagej.nih.gov/ij/). First a consistent region of interest (ROI) for each side of the implant was defined (HP). The ROI (output in pixels) corresponded to the implant surface of the respective site without the apical part $(6 \mathrm{~mm})$, which was included circumferentially in all models. Then, the relevant implant surface was, according to the photographed side, selected by overlay of the corresponding ROI. The remaining red color was marked within this area, and the number of pixels of the red color remnants was displayed. This number was multiplied by 100 and divided by the total number of pixels in the ROI resulting in a percentage $(\%)$. This procedure was repeated for the second side of the implant. The mean of both percentages was then calculated in order to obtain a total value of color remnants (\%) of the whole selected implant surface. Basic values (brightness, contrast, sharpness) were not changed during the entire procedure.
In addition, SEM images (Philips XL 30 with lanthanum hexaboride cathode, $20 \mathrm{kv}, 10 \mathrm{~mm}$ distance, Philips, Amsterdam, The Netherlands) were exemplarily obtained after instrumentation of the machined and rough surfaces of one untreated (reference) and one non-surgically and surgically treated implant for each air-polishing method (GAPA1-3) (CR; magnification $1 \times 1000$ and $1 \times 10,000)$ [17]. All samples were gold coated with a layer thickness of approximately $50 \mathrm{~nm}$ using an automatic sputtercoater (MSC2, KDF Electronic \& Vacuum Services Inc., New Jersey, USA) (Figs. 5 and 6).

\section{Statistical evaluation}

The statistical evaluation followed the protocol by Keim et al. [17]. The implant was considered as statistical unit. The
Fig. 4 Detailed images of the cleaned surfaces according to treatment modality (GAPA 1-3) and defect angle

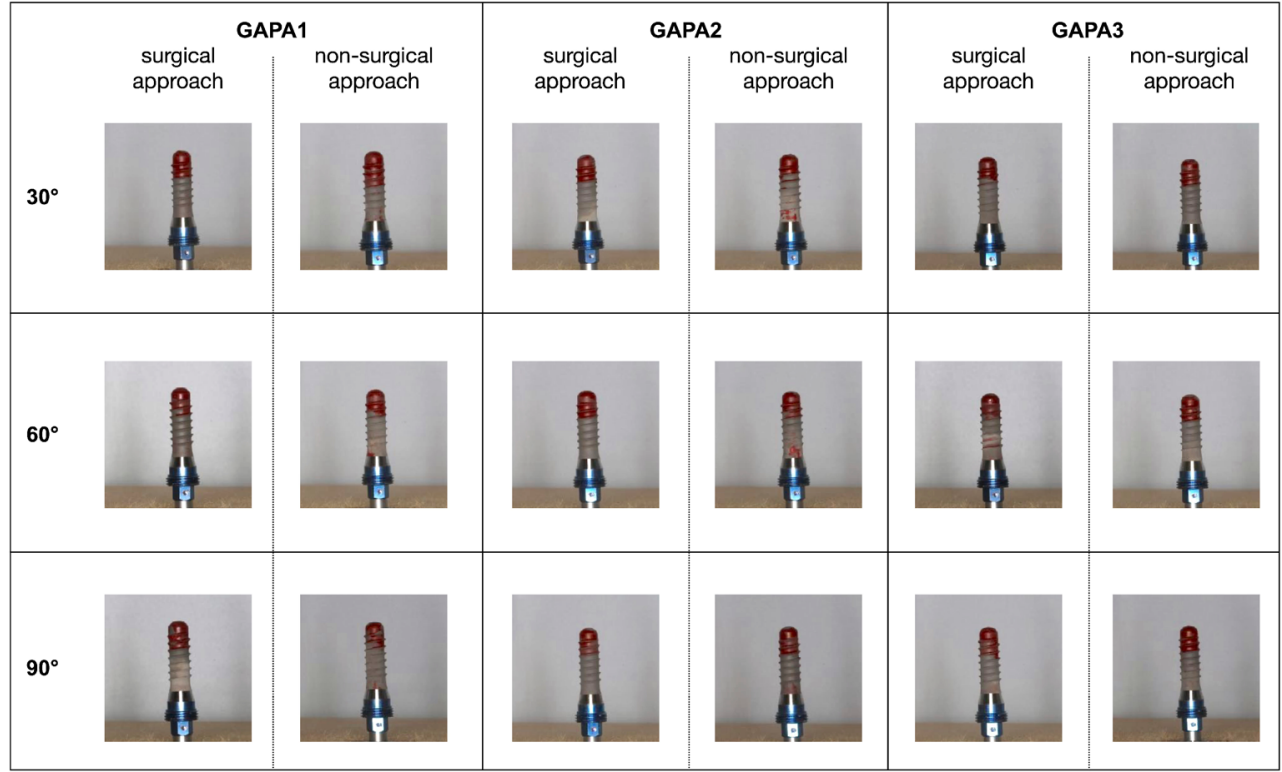


Fig. 5 a Scanning electron microscopy images of untreated (reference) and non-surgically treated macro-threads of the implant surfaces by different instruments at magnification of $\times 1000$ and $\times 10.000$. b Scanning electron microscopy images of untreated (reference) and nonsurgically treated machined collar of the implant by different instruments at magnification of $\times 1000$ and $\times 10.000$
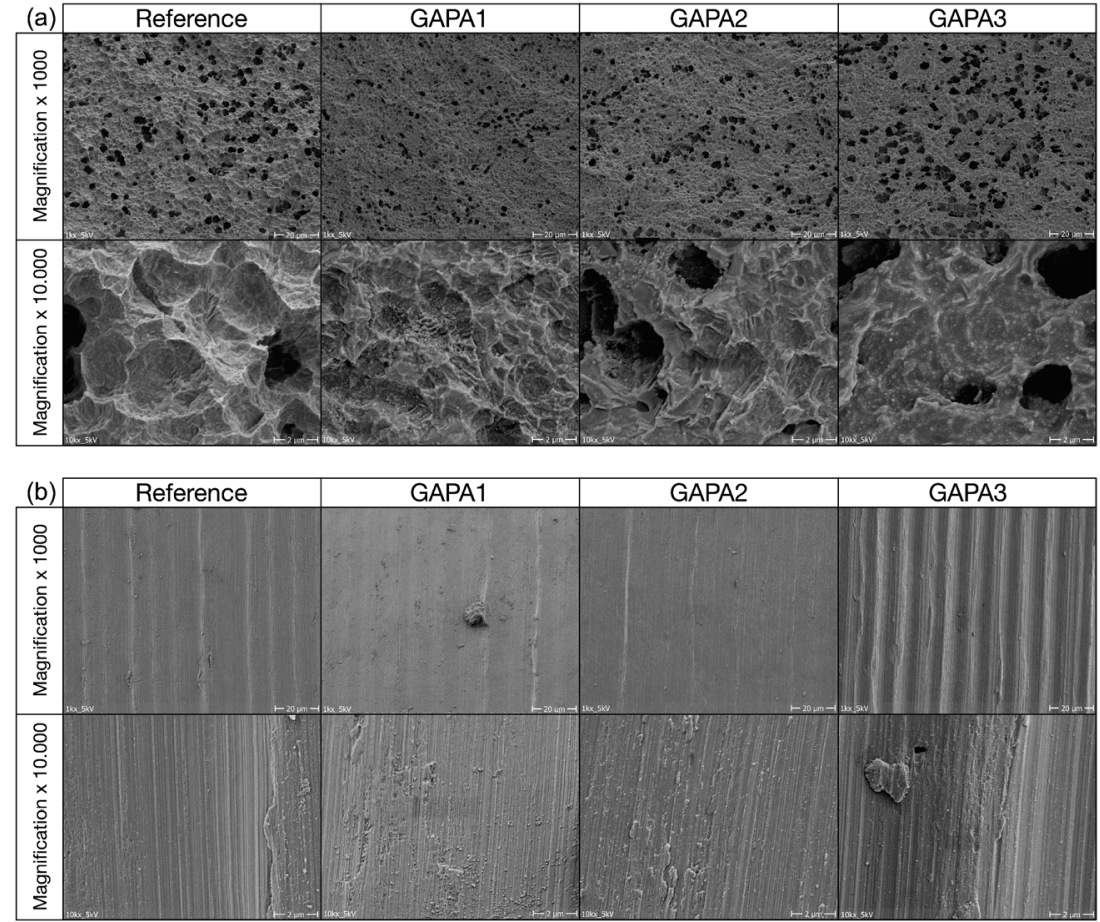

percentage of non-cleaned surface was calculated for each implant (VT). First, the data were tested for normal distribution using the Kolmogorov-Smirnov test. Depending on this, descriptive data [mean value, medians, lower/upper quartiles, interquartile ranges (IR) and standard deviation] were analyzed for the cleaning methods and defect angulations according to the surgical or non-surgical simulation. Group comparisons were carried out using Kruskal-Wallis test for non-normally distributed data. The distribution of color remnants according to the different air-polishing device combinations (Fig. 7) and to the non-surgical and surgical approach (Fig. 8) are shown as box plot diagrams (wide black line, median; box, 25-75\% range of all values; whiskers, range of all values without outliers; circle, outliers; asterisk, extreme
Fig. 6 a Scanning electron microscopy images of untreated (reference) and non-surgically treated macro-threads of the implant surfaces by different instruments at magnification of $\times 1000$ and $\times 10.000$. b Scanning electron microscopy images of untreated (reference) and nonsurgically treated machined collar of the implant by different instruments at magnification of $\times 1000$ and $\times 10.000$
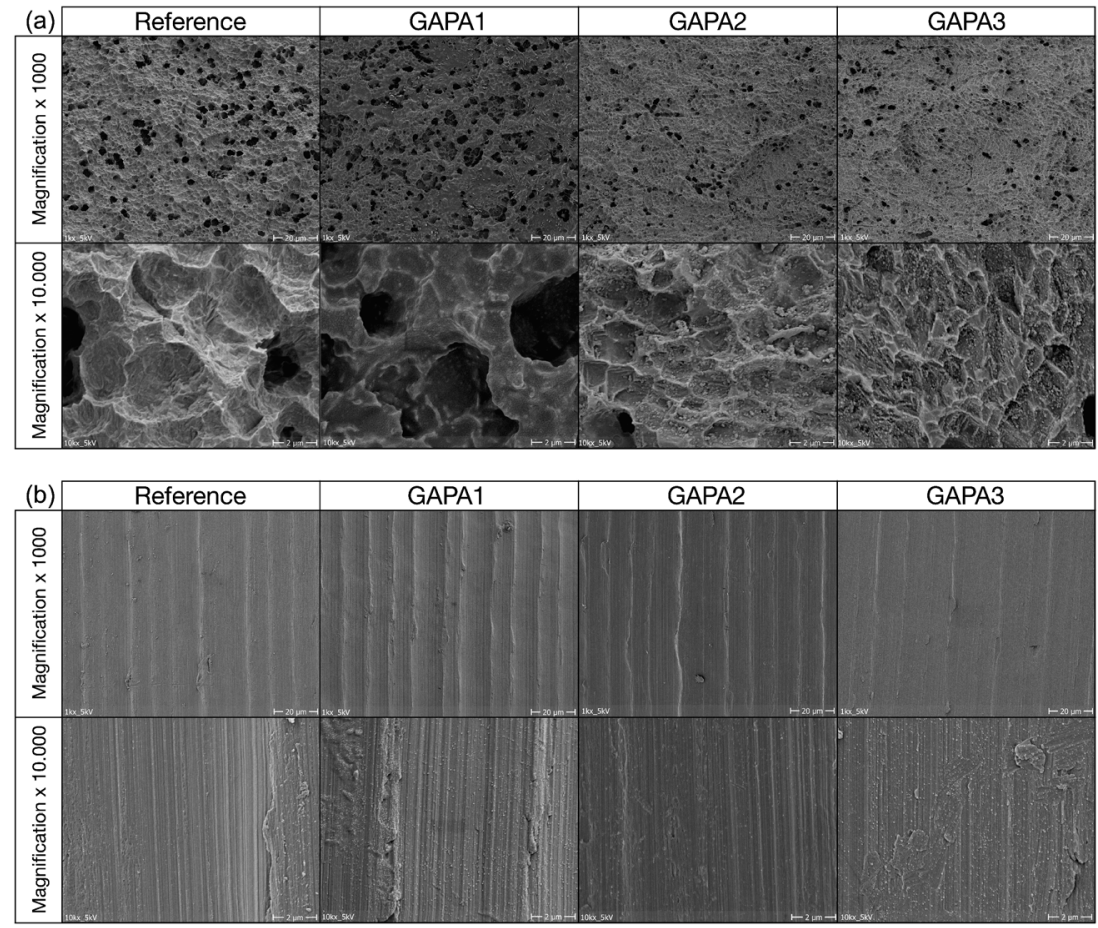
Fig. 7 a Distribution of color remnants for different nonsurgical treatment methods according to each defect angulation. b Distribution of color remnants for surgical different treatment methods according to each defect angle
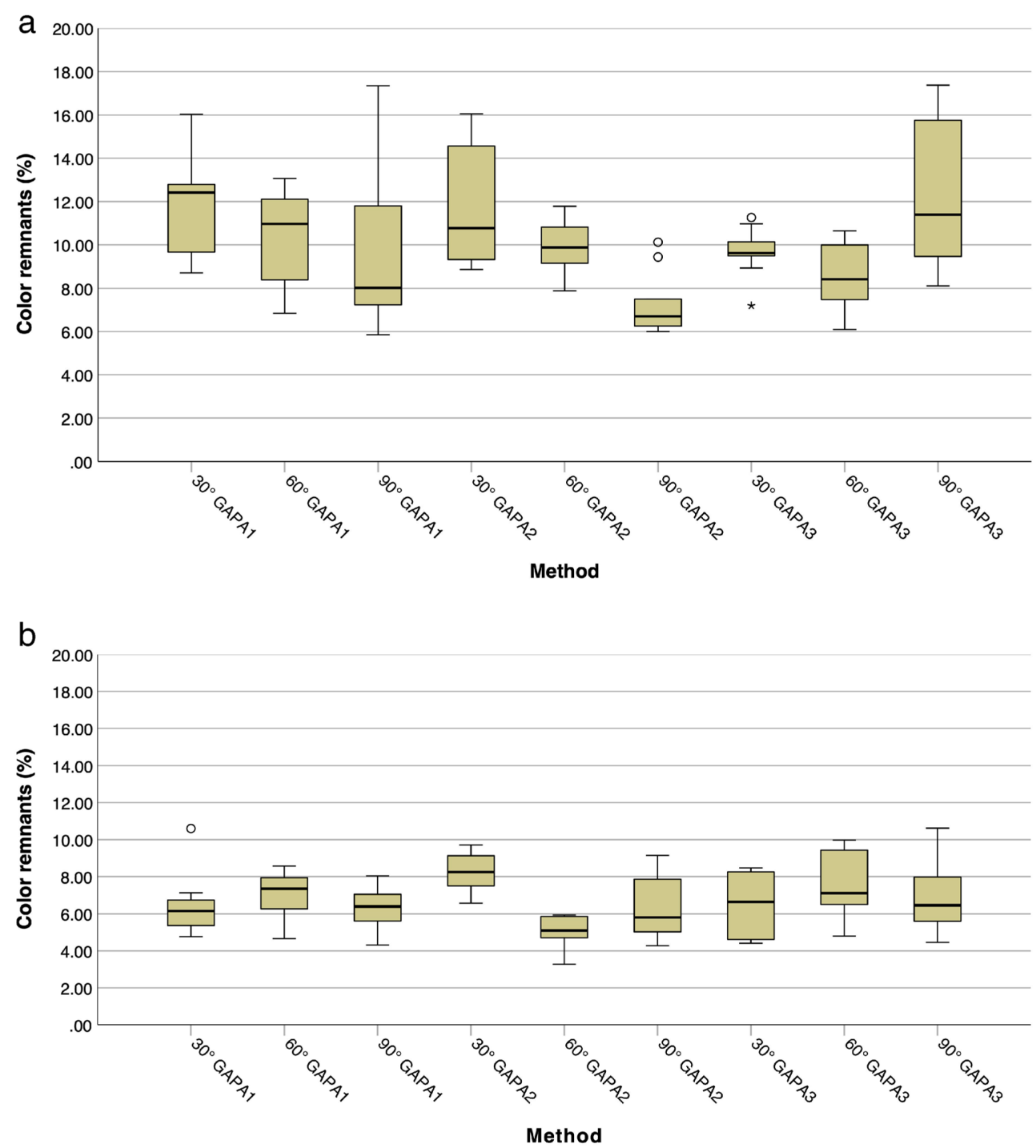

outlier). By defining a $p$ value $<0.001$ as the significance level, multiple testing (Bonferroni correction [33]; 36 comparisons in the surgical or non-surgical group) was addressed. Group comparisons between the entirety of all surgical and non-surgical procedures were carried out by Mann-Whitney $U$ test.

The statistical evaluation was carried out using the $\mathrm{IBM}^{\circledR}$ SPSS $^{\circledR}$ Statistics 26 software package (IBM, Chicago, Illinois, USA).

The study was planned in compliance with the appropriate EQUATOR guidelines.

\section{Results}

The results of the post-hoc testing of the device settings are shown in Table 1.
The overall comparison of the non-surgical approaches [mean \pm standard deviation, $10.13 \pm 2.75 \%$ (median, $9.68 \%$; IR, 3.49)] with the surgical approaches $[6.68 \pm$ $1.66 \%(6.57 \%$; IR, 2.53)] is significantly $(p<0.001)$ in favor of the surgical approach (Fig. 8). The box plot diagrams show no trend in cleaning efficacy regarding the applied air-polishing device combinations for either the non-surgical or the surgical approach (Fig. 7a/b). Nevertheless, the average smaller range of color remnants in Figs. $7 \mathrm{~b}$ and 8 (range surgical approach: $3.27-10.62 \%$ ) indicate a higher reproducibility of the cleaning results compared to the larger range (range non-surgical approach, 5.85-17.37\%) in Figs. 7a and 8.

None of the investigated implant surfaces were completely free $(0 \%)$ of color remnants. Residual color on the lower $6 \mathrm{~mm}$ of the implants was the result of a non-accessible area for cleaning because the implants were surrounded by the models in this part (Figs. 1 and 2). 
Fig. 8 Distribution of color remnants according to each treatment approach

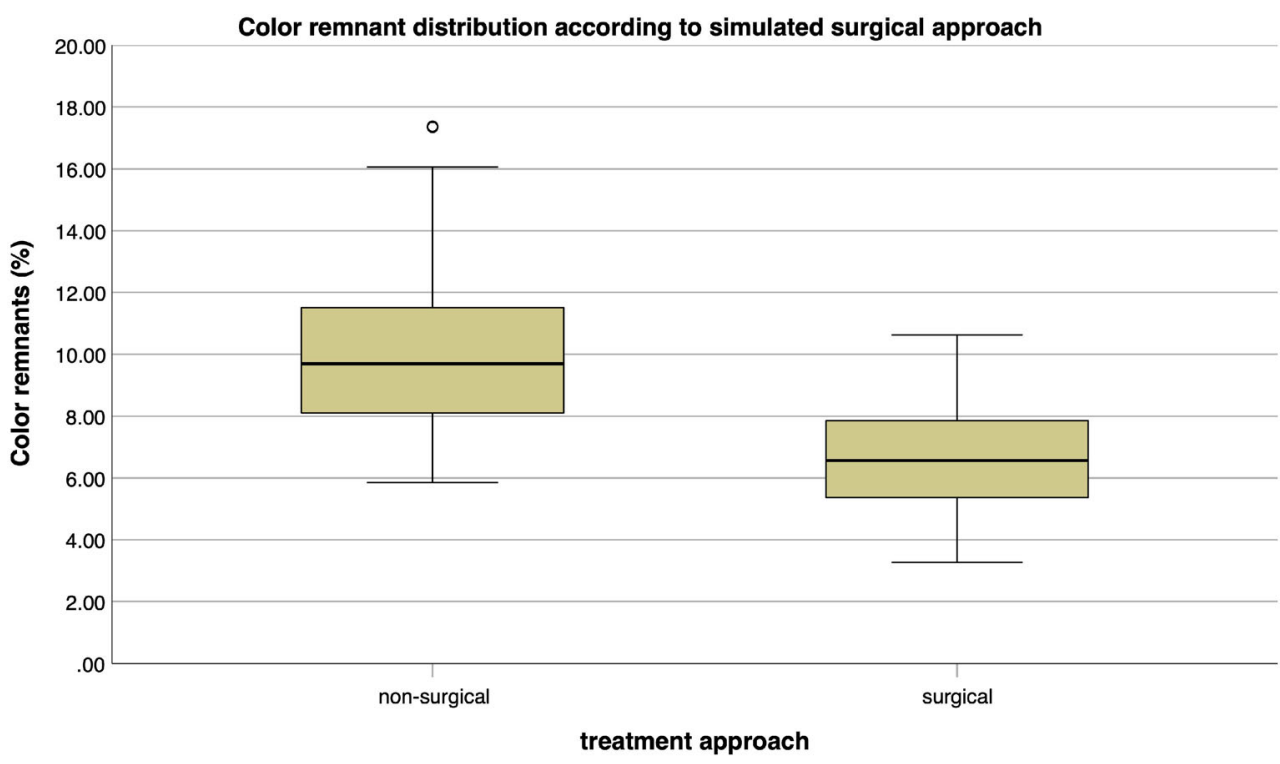

The cleaning efficiency did not show any significant difference $(p<0.001)$ for each surgical or non-surgical cleaning method within each defect configuration (Table $2 \mathrm{a} / \mathrm{b}$ ). Within the individual air-polishing device combinations, there was only a significant difference between GAPA2 in the nonsurgical approach (Table 2a) between $30^{\circ}$ (median, $10.77 \%$; IR, 5.48) and $90^{\circ}(6.71 \%$; IR, 1.77) and in the surgical approach (Table 2b) between $30^{\circ}\left(8.25 \%\right.$; IR, 1.77) and $60^{\circ}$ (5.10\%; IR, 1.29).

Consequently, for the majority of all comparisons within the various air-polishing device combinations and within the three different defect angulations, no differences in cleaning efficacy were shown. The null hypothesis was rejected.

All SEM images confirm the complex surface morphology of the selected implant system. Cleaning with air-polishing devices showed no serious surface damage in the obtained SEM images, neither in the area of the machined nor in the area of the rough implant surface (Figs. 5 and 6). The machined rings were smoothened after air-polishing indicating a slight modification of the surface.

\section{Discussion}

The aim of this study was to compare the efficacy of three different combinations of air-polishing methods for implant surface decontamination in different non-surgical and surgical in vitro defect models $\left(30^{\circ}, 60^{\circ}, 90^{\circ}\right)$. Overall, the surgical approaches were significantly superior $(p<0.001)$ to the non-surgical ones. The low color remnant value for all methods and approaches indicates a good cleaning efficacy, even if no implant could be completely freed $(0 \%)$ from the color. Among the three investigated methods (GAPA1-3), no significant differences occurred. Only GAPA2 showed significant differences $(p<0.001)$ within the methods in the non-surgical $\left(30^{\circ}-90^{\circ}\right)$ and surgical procedure $\left(30^{\circ}-60^{\circ}\right)$. The null hypothesis was rejected.

The main reason for the use of nozzle tips in the nonsurgical as well as in the surgical approach was the comparability to other studies $[17,19]$. In addition, peri-implant defects are typically shaped around implants in spite of flap mobilization and, depending on the depth, a nozzle tip may still facilitate better accessibility.

Table 1 Post-hoc testing of air-polishing device settings

Post-hoc testing of air-polishing device settings

\begin{tabular}{llllllllllllllll}
\hline Air-polishing device combination & \multicolumn{2}{l}{$\begin{array}{l}\text { Water ejection } \\
\text { (ml/min) }\end{array}$} & & & \multicolumn{3}{c}{$\begin{array}{l}\text { Powder emission rate } \\
\text { (g/min) }\end{array}$} & & \multicolumn{4}{c}{$\begin{array}{l}\text { Drive air-pressure } \\
\text { (bar) }\end{array}$} \\
\hline & I & II & III & Mean \pm SD & I & II & III & Mean \pm SD & I & II & III & Mean \pm SD \\
GAPA1 & 49.0 & 56.0 & 65.0 & $56.7 \pm 8.02$ & 3.54 & 3.51 & 2.26 & $4.28 \pm 0.73$ & 3.4 & 3.5 & 3.5 & $3.47 \pm 0.06$ \\
GAPA2 & 60.0 & 65.0 & 63.0 & $62.7 \pm 2.52$ & 2.80 & 2.29 & 2.51 & $2.53 \pm 0.26$ & 3.5 & 3.6 & 3.5 & $3.53 \pm 0.06$ \\
GAPA3 & 56.0 & 56.0 & 57.0 & $56.3 \pm 0.58$ & 3.86 & 4.82 & 3.81 & $4.16 \pm 0.57$ & 3.5 & 3.6 & 3.6 & $3.57 \pm 0.06$ \\
\hline
\end{tabular}

$\mathrm{SD}=$ standard deviation 


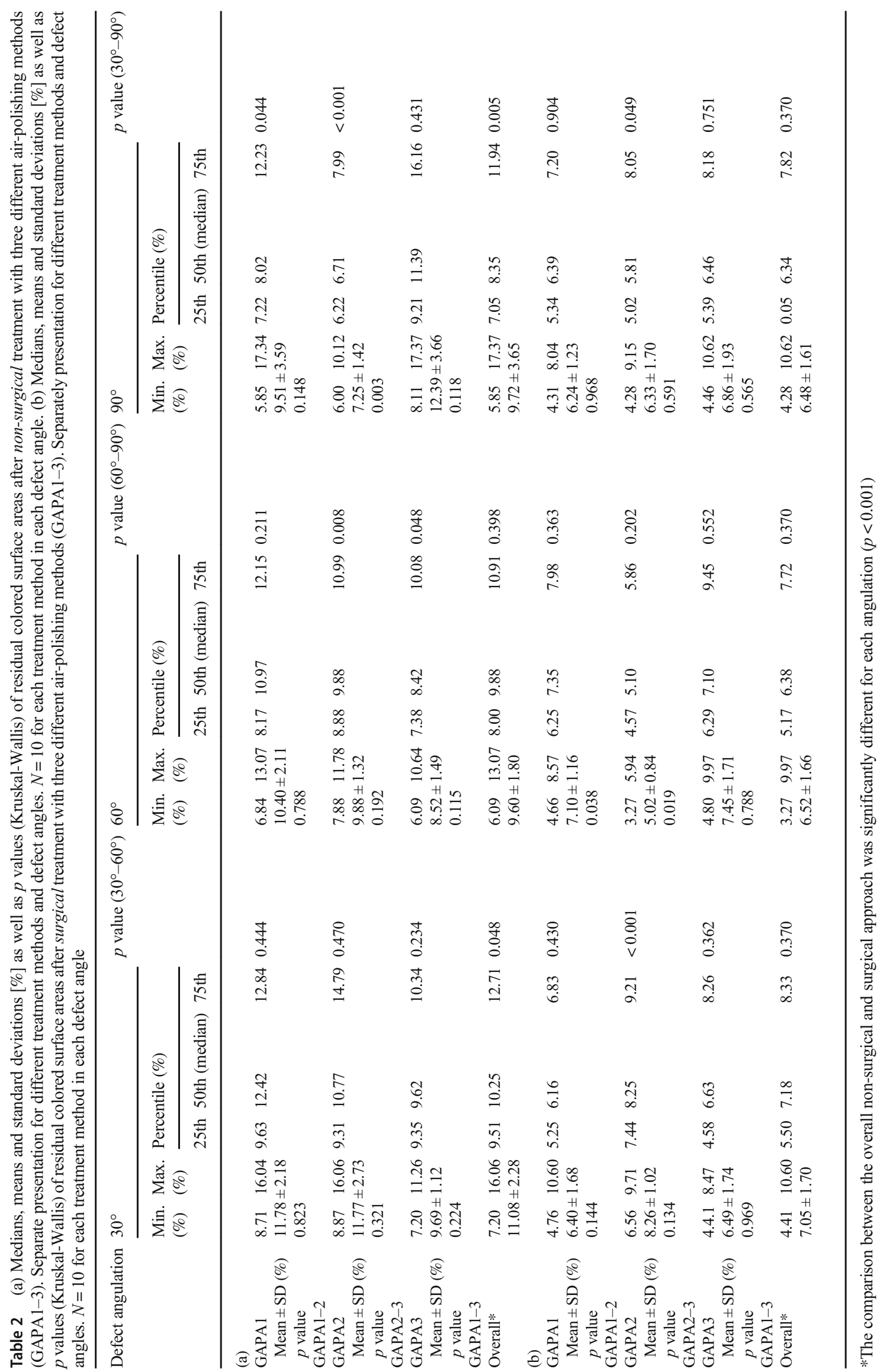


The authors want to anticipate that, according to the current state of affairs, the surgical application of air-polishing devices represents an off-label use due to the lack of sterility, which is why an in vitro investigation was initially carried out.

As Petersilka in 2011 described [34], air-polishing with its powder-water ejection is subject to the so-called ricochet effect, which may have an influence on the cleaning efficacy. For particles that hit a hard surface, this effect describes an uncontrolled rebound, bounce, or skip off a surface depending on its texture. The fact that there were no significant differences within the respective defect angulations suggests that neither the powder used nor the geometry of the nozzle applied have a major influence on the results achieved. Also, the defect geometry obviously no longer plays a major role in the uniform use of air-polishing devices. Only the GAPA2 combination showed significant differences $(p<0.001)$ in cleaning efficiency (non-surgical, $30^{\circ}-90^{\circ}$; surgical, $30^{\circ}-$ $60^{\circ}$ ). On the one hand, this may be due to the narrow defect angle of $30^{\circ}$ involved in both cases, which may be more difficult to access. On the other hand, the slightly different posthoc tests of the device settings of GAPA2 compared to GAPA1 and GAPA3 could have influenced this.

The superiority of air-polishing methods [35], but especially of glycine-based air-polishing devices, over the use of rigid instruments (e.g. steel curettes, sonic scaler) with regard to cleaning efficacy and less surface damage in non-surgical/ covered and surgical/open in vitro models has recently been repeatedly proven $[17,18,25,36]$. Therefore, the present in vitro study deals with the efficacy of different glycinebased air-polishing methods in two simulated treatment approaches (non-surgical/covered and surgical/open).

With regard to the non-surgical procedure, 20 implants per angulation were cleaned with glycine-based air-polishing in a very similar study [18]. The implant systems used were also very similar in micro and macro structure. However, the results are significantly different, when considering both the data based on the use of the same instruments (GAPA2) and the overall average data. While Ronay et al. [18] found $40.15 \pm 10.40 \%$ $\left(30^{\circ}\right), 40.30 \pm 7.12 \%\left(60^{\circ}\right)$, and $21.20 \pm 8.96 \%\left(90^{\circ}\right)$ color remnants, the average values of our investigation were $11.08 \pm$ $2.28 \%\left(30^{\circ}\right), 9.60 \pm 1.80\left(60^{\circ}\right)$, and $9.72 \pm 3.65 \%\left(90^{\circ}\right)$.

Regarding the surgical procedure, the comparison to Sahrmann et al. [19] and Keim et al. [17] can be made, who also used similar experimental setups. The former investigation reports $16.1 \pm 3.7 \%\left(30^{\circ}\right), 12.7 \pm 2.8 \%\left(60^{\circ}\right)$, or $5.0 \pm$ $1.4 \%\left(90^{\circ}\right)$ color remnant, and Keim et al. [17] showed color remnants in $8.03 \pm 2.43 \%\left(30^{\circ}\right), 0.13 \pm 0.26 \%\left(60^{\circ}\right)$, and 0.58 $\pm 0.88 \%\left(90^{\circ}\right)$ on the corresponding implants. The present study found on average $7.05 \pm 1.70 \%\left(30^{\circ}\right), 6.52 \pm 1.66 \%$ $\left(60^{\circ}\right)$, and $6.48 \pm 1.61 \%\left(90^{\circ}\right)$ color remnants on the implant surfaces after the surgical/open approach.

In the non-surgical comparison, a different implant system was used in this study than in Ronay et al. [18]. Both implants are similar with a machined implant shoulder (Ronay et al. [18], $1.0 \mathrm{~mm}$; present study, $1.8 \mathrm{~mm}$ ) and a rough part underneath with macro-threads at quite similar distances (Ronay et al. [18], $1.0 \mathrm{~mm}$; present study, $1.25 \mathrm{~mm}$ ) and with the same thread depth $(0.35 \mathrm{~mm})$. Nevertheless, the two systems differed in their surface properties. The surface roughness of the sand-blasted thermal acid-etched implants used by Ronay et al. [18] is $R_{\mathrm{a}}=2.35 \mu \mathrm{m}$. In the present study, the sandblasted and acid-etched implants had an average roughness of $R_{\mathrm{a}}=1.69 \mu \mathrm{m}$. This different surface roughness may partially explain the different results. Due to the rougher surface in Ronay et al. [18], the adhesion of the color used may have been more pronounced than in the present study and therefore was more difficult to remove. Another important difference between the two studies is that Ronay et al. [18] carried out the procedure randomly, while there was no randomization in this study and only one examiner carried out all cleaning procedures and analyses.

Both studies used mucosa masks made from different materials, so that the rigidity and thus the resistance to the instruments inserted between the implant and the mask were different. The width of the bone defect models and thus the thickness of the mucosal mask may play an important role, which was not specified in either study. The thicker it was, the less firmly it was pressed onto the implant surface during cleaning (while it was held by the examiner). Too much pressure could position the respective nozzle incorrectly and the cleaning effect could suffer. The adaptation of the mucosal mask on the model was identical (it was just put over the model). Furthermore, the material used for the mucosal mask is different. Ronay et al. have used a material more similar to human tissue (ballistic gelatine), but in combination with the abovementioned pressure the effect cannot be clearly distinguished.

Looking at the surgical/open procedure, it can be seen that the results in these studies overall are closer together [17, 19]. Nevertheless, differences can also be found here. The implants were quite similar in macroscopic structure (Sahrmann et al., [19]: thread distance $1.25 \mathrm{~mm}$, thread depth $0.35 \mathrm{~mm}$, machined collar $1.8 \mathrm{~mm}$; Keim et al. [17]: thread distance $0.6 \mathrm{~mm}$, thread depth $0.32 \mathrm{~mm}$, machined collar $1.5 \mathrm{~mm}$; present study: thread distance $1.25 \mathrm{~mm}$, thread depth $0.35 \mathrm{~mm}$, machined collar $1.8 \mathrm{~mm}$ ). However, the study with the highest color remnant values used the implant system with the highest surface roughness (Sahrmann et al. [19]: $2.93 \mu \mathrm{m}$; Keim et al. [17]: $0.76 \mu \mathrm{m}$; present study: $1.69 \mu \mathrm{m}$; values were presented by Sammonos et al. [37]). The results of Keim et al. [17] and this study are less different, which may be due to the fact that each implant was used only once in both studies. Sahrmann et al. [19] have used the implants several times, which could possibly have influenced their surface roughness/texture [38].

In general, the studies by Ronay et al. [18] and Sahrmann et al. [19] differ from those of Keim [17] and the present 
investigation in that no uniform method for analyzing the color remnants was applied. In addition, the device settings (drive air-pressure, water ejection, powder emission) as well as the depth, the design, and movement of the nozzle play an important role in the defect to be cleaned [39]. The device settings were measured post-hoc, but cannot be compared because they are not reported in the other studies [17-19]. The nozzle used in the combinations GAPA1 and GAPA2 has more stable walls than the nozzle from the combination GAPA3 and three outlet openings ( $2 x$ laterally, $1 x$ vertically) for the powder-water jet mixture, while the nozzle from the GAPA 3 combination has two outlet openings (1x laterally, $1 \mathrm{x}$ vertically). With the GAPA1 and GAPA2 nozzle, the powderwater jet mixture hits the implant surface directly through a side outlet, while with the GAPA3 nozzle it does not directly hit the implant surface but emerges laterally from it. With the GAPA3 nozzle, a mixture is not ejected; instead, water and powder are guided separately within the nozzle. The water finally emerges vertically, and the powder emerges laterally. Due to its slim design, the GAPA3 nozzle rotates laterally when performing the non-surgical procedure, as soon as it is inserted into the pocket. This is not the case with the nozzle used in the GAPA 1 and GAPA2 combination due to its higher rigidity.

In general, various systematic reviews $[9,11,21]$ as well as recent clinical studies [23, 40] show advantageous results in the use of glycine-based air-polishing devices for the (non-)surgical treatment of peri-implantitis. However, their ability to restore the biocompatibility of the implant surface [41] and to maintain achieved results in the long term [42] are questioned. Assuming that more effective surface decontamination would also mean clinically better results, then air-polishing would probably lead to improved therapy results. However, the extrapolation of these in vitro results to the clinic is not allowed.

The present study presupposed that removal of the suprastructure from the implants for a more straightforward accessibility of the implant surface is possible. Otherwise poorer results due to the limited accessibility may have been achieved [43]. In everyday clinical practice, missing removability of a cemented suprastructure should be considered.

SEM images of this study confirm other investigations showing only slight changes of implant surface morphology after application of glycine-based air-polishing devices [17-19, 26-28, 41].

A current review on the in vitro efficacy of air-polishing devices on titanium implant surface damages concludes that they are less damaging compared to harder and larger-sized powders such as sodium bicarbonate especially when using glycine-based powder types [41]. These results are confirmed by recent in vitro $[26,27]$ and in vivo [28] studies. On the other hand, there are indications that coarser powder types can achieve a higher cleaning efficacy than finer ones [27]. Although the ability of glycine-based powders to maintain biocompatibility when applied to titanium surfaces is questioned [41], it still appears more likely than with major damages such as, e.g. caused by steel curettes [17-19].

A limitation of the present study is biofilm imitation by use of color without simulation of further oral cavity-specific influences. Nevertheless, this type of in vitro model and the use of color as "artificial plaque" have prevailed [17-19, 25]. Further, the rigidity and re-use of the mucosa mask differ from the oral mucosa which may lead to results different from the oral cavity. Photographic analysis from a single angle may cause less accurate differentiation of color remnants on the apically and coronally facing site of the threads than in previous investigations $[16,25]$. The fact that one examiner (VT) did both the implant cleaning and the subsequent analysis without randomization may lead to bias.

In summary, the results of this in vitro study show that the use of glycine-based air-polishing devices, regardless of the manufacturer and largely also of the defect geometry, achieves in a non-surgical/covered and surgical/open approach a high cleaning efficacy according to the chosen implant system. Nevertheless, a complete surface decontamination was not achieved with any device.

Acknowledgements The authors would like to thank DENTAL RATIO ${ }^{\circledR}$ and NSK Europe GmbH for material support. Special thanks go to Dominik Giesa for the design and fabrication of the in vitro models and to Robert Arnold for designing the mucosa masks. This study was performed for a thesis (Vivian Tuchscheerer) for a Master of Science in Periodontology and Implant Therapy [German Society of Periodontology (DG PARO) and Dresden International University (DIU)].

Author contribution All authors contributed substantially to the interpretation of the data for the work, they contributed to drafting and critically revising the manuscript, and they gave their final approval of the version to be published and agreed to be accountable for all aspects of the work. Additionally, H.P., O.Z., and P.E. conceived the ideas for the concept and design of the study; V.T. collected the data; C.R. took the scanning electron microscope images; B.D. complied methodical approaches; H.P. analyzed data, secured funding, and managed the group; H.P. led the writing.

Funding information Open Access funding provided by Projekt DEAL.

\section{Compliance with ethical standards}

Conflict of interest The authors declare that they have no conflict of interest. This study was in part self-funded by the authors and their institutions. The treated implants in the present study were kindly provided by DENTAL RATIO ${ }^{\circledR}$ (Langenfeld, Germany). NSK Europe GmbH (Eschborn, Germany) provided the Perio-Mate including glycine powder and nozzle tips.

Ethics approval and consent to participate This is article does not contain any studies with human participants or animals performed by any of the authors. An exemption letter from the Institutional Review Board for 
Human Studies of the Medical Faculty of the Goethe-University Frankfurt/Main has been provided approving that no ethical concerns are raised. For this type of study, formal consent is not required.

Open Access This article is licensed under a Creative Commons Attribution 4.0 International License, which permits use, sharing, adaptation, distribution and reproduction in any medium or format, as long as you give appropriate credit to the original author(s) and the source, provide a link to the Creative Commons licence, and indicate if changes were made. The images or other third party material in this article are included in the article's Creative Commons licence, unless indicated otherwise in a credit line to the material. If material is not included in the article's Creative Commons licence and your intended use is not permitted by statutory regulation or exceeds the permitted use, you will need to obtain permission directly from the copyright holder. To view a copy of this licence, visit http://creativecommons.org/licenses/by/4.0/.

\section{References}

1. Daubert DM, Weinstein BF (2019) Biofilm as a risk factor in implant treatment. Periodontol 2000 81(1):29-40. https://doi.org/10. 1111/prd.12280

2. Berglundh T, Armitage G, Araujo MG, Avila-Ortiz G, Blanco J, Camargo PM, Chen S, Cochran D, Derks J, Figuero E, Hammerle CHF, Heitz-Mayfield LJA, Huynh-Ba G, Iacono V, Koo KT, Lambert F, McCauley L, Quirynen M, Renvert S, Salvi GE, Schwarz F, Tarnow D, Tomasi C, Wang HL, Zitzmann N (2018) Peri-implant diseases and conditions: consensus report of workgroup 4 of the 2017 World Workshop on the Classification of Periodontal and Peri-Implant Diseases and conditions. J Periodontol 89(Suppl 1):S313-S318. https://doi.org/10.1002/ JPER.17-0739

3. Salvi GE, Ramseier CA (2015) Efficacy of patient-administered mechanical and/or chemical plaque control protocols in the management of peri-implant mucositis. A systematic review. J Clin Periodontol 42(Suppl 16):S187-S201. https://doi.org/10.1111/ jcpe. 12321

4. Heitz-Mayfield LJ (2008) Peri-implant diseases: diagnosis and risk indicators. J Clin Periodontol 35(8 Suppl):292-304. https://doi.org/ 10.1111/j.1600-051X.2008.01275.x

5. Pjetursson BE, Helbling C, Weber HP, Matuliene G, Salvi GE, Bragger U, Schmidlin K, Zwahlen M, Lang NP (2012) Periimplantitis susceptibility as it relates to periodontal therapy and supportive care. Clin Oral Implants Res 23(7):888-894. https:// doi.org/10.1111/j.1600-0501.2012.02474.x

6. Roccuzzo M, Bonino L, Dalmasso P, Aglietta M (2014) Long-term results of a three arms prospective cohort study on implants in periodontally compromised patients: 10-year data around sandblasted and acid-etched (SLA) surface. Clin Oral Implants Res 25(10):1105-1112. https://doi.org/10.1111/clr.12227

7. Sanz-Martin I, Cha JK, Yoon SW, Sanz-Sanchez I, Jung UW (2019) Long-term assessment of periodontal disease progression after surgical or non-surgical treatment: a systematic review. J Periodontal Implant Sci 49(2):60-75. https://doi.org/10.5051/jpis. 2019.49.2.60

8. Lin CY, Chen Z, Pan WL, Wang HL (2019) The effect of supportive care in preventing peri-implant diseases and implant loss: a systematic review and meta-analysis. Clin Oral Implants Res 30(8):714-724. https://doi.org/10.1111/clr.13496

9. Schwarz F, Becker K, Renvert S (2015) Efficacy of air polishing for the non-surgical treatment of peri-implant diseases: a systematic review. J Clin Periodontol 42(10):951-959. https://doi.org/10. $1111 /$ jcpe. 12454
10. Heitz-Mayfield LJA, Salvi GE (2018) Peri-implant mucositis. J Periodontol 89(Suppl 1):S257-S266. https://doi.org/10.1002/ JPER.16-0488

11. Suarez-Lopez Del Amo F, Yu SH, Wang HL (2016) Non-surgical therapy for peri-implant diseases: a systematic review. J Oral Maxillofac Res 7(3):e13. https://doi.org/10.5037/jomr.2016.7313

12. Wang CW, Renvert S, Wang HL (2019) Nonsurgical treatment of periimplantitis. Implant Dent 28(2):155-160. https://doi.org/10. 1097/ID.0000000000000846

13. Schwarz F, Schmucker A, Becker J (2015) Efficacy of alternative or adjunctive measures to conventional treatment of peri-implant mucositis and peri-implantitis: a systematic review and meta-analysis. Int J Implant Dent 1(1):22. https://doi.org/10.1186/s40729-0150023-1

14. Renvert S, Polyzois I, Claffey N (2012) Surgical therapy for the control of peri-implantitis. Clin Oral Implants Res 23(Suppl 6):84 94. https://doi.org/10.1111/j.1600-0501.2012.02554.x

15. Polak D, Maayan E, Chackartchi T (2017) The impact of implant design, defect size, and type of superstructure on the accessibility of nonsurgical and surgical approaches for the treatment of periimplantitis. Int J Oral Maxillofac iImplants 32(2):356-362. https:// doi.org/10.11607/jomi.4781

16. Steiger-Ronay V, Merlini A, Wiedemeier DB, Schmidlin PR, Attin T, Sahrmann P (2017) Location of unaccessible implant surface areas during debridement in simulated peri-implantitis therapy. BMC Oral Health 17(1):137. https://doi.org/10.1186/s12903-0170428-8

17. Keim D, Nickles K, Dannewitz B, Ratka C, Eickholz P, Petsos H (2019) In vitro efficacy of three different implant surface decontamination methods in three different defect configurations. Clin Oral Implants Res 30(6):550-558. https://doi.org/10.1111/clr.13441

18. Ronay V, Merlini A, Attin T, Schmidlin PR, Sahrmann P (2017) In vitro cleaning potential of three implant debridement methods. Simulation of the non-surgical approach. Clin Oral Implants Res 28(2):151-155. https://doi.org/10.1111/clr.12773

19. Sahrmann P, Ronay V, Hofer D, Attin T, Jung RE, Schmidlin PR (2015) In vitro cleaning potential of three different implant debridement methods. Clin Oral Implants Res 26(3):314-319. https://doi. org/10.1111/clr.12322

20. De Bartolo AM, Veitz-Keenan A (2019) Inconclusive evidence of treatment modalities for peri-implantitis. Evid Based Dent 20(1): 24-25. https://doi.org/10.1038/s41432-019-0007-8

21. Muthukuru M, Zainvi A, Esplugues EO, Flemmig TF (2012) Nonsurgical therapy for the management of peri-implantitis: a systematic review. Clin Oral Implants Res 23(Suppl 6):77-83. https://doi. org/10.1111/j.1600-0501.2012.02542.x

22. Lin GH, Suarez Lopez Del Amo F, Wang HL (2018) Laser therapy for treatment of peri-implant mucositis and peri-implantitis: an American Academy of periodontology best evidence review. J Periodontol 89(7):766-782. https://doi.org/10.1902/jop.2017. 160483

23. Toma S, Brecx MC, Lasserre JF (2019) Clinical evaluation of three surgical modalities in the treatment of peri-implantitis: a randomized controlled clinical trial. J Clin Med 8(7). https://doi.org/10. 3390/jcm8070966

24. Shiau HJ (2019) Limited evidence suggests that adjunctive antimicrobial photodynamic therapy may not provide additional clinical benefit to conventional instrumentation strategy alone in periodontitis and peri-implantitis patients. J Evid Based Dent Pract 19(4): 101346. https://doi.org/10.1016/j.jebdp.2019.101346

25. Sahrmann P, Ronay V, Sener B, Jung RE, Attin T, Schmidlin PR (2013) Cleaning potential of glycine air-flow application in an in vitro peri-implantitis model. Clin Oral Implants Res 24(6):666670. https://doi.org/10.1111/j.1600-0501.2012.02445.x

26. Cha JK, Paeng K, Jung UW, Choi SH, Sanz M, Sanz-Martin I (2019) The effect of five mechanical instrumentation protocols on 
implant surface topography and roughness: a scanning electron microscope and confocal laser scanning microscope analysis. Clin Oral Implants Res 30(6):578-587. https://doi.org/10.1111/clr. 13446

27. Matsubara VH, Leong BW, Leong MJL, Lawrence Z, Becker T, Quaranta A (2019) Cleaning potential of different air abrasive powders and their impact on implant surface roughness. Clin Implant Dent Relat Res 22:96-104. https://doi.org/10.1111/cid.12875

28. Cochis A, Fini M, Carrassi A, Migliario M, Visai L, Rimondini L (2013) Effect of air polishing with glycine powder on titanium abutment surfaces. Clin Oral Implants Res 24(8):904-909. https:// doi.org/10.1111/j.1600-0501.2012.02490.x

29. Petersilka GJ, Bell M, Haberlein I, Mehl A, Hickel R, Flemmig TF (2003) In vitro evaluation of novel low abrasive air polishing powders. J Clin Periodontol 30(1):9-13. https://doi.org/10.1034/j.1600051x.2003.300102.x

30. Petersilka GJ, Steinmann D, Haberlein I, Heinecke A, Flemmig TF (2003) Subgingival plaque removal in buccal and lingual sites using a novel low abrasive air-polishing powder. J Clin Periodontol 30(4):328-333. https://doi.org/10.1034/j.1600-051x.2003.00290.x

31. Petersilka GJ, Tunkel J, Barakos K, Heinecke A, Haberlein I, Flemmig TF (2003) Subgingival plaque removal at interdental sites using a low-abrasive air polishing powder. J Periodontol 74(3): 307-311. https://doi.org/10.1902/jop.2003.74.3.307

32. Petersilka G, Faggion CM Jr, Stratmann U, Gerss J, Ehmke B, Haeberlein I, Flemmig TF (2008) Effect of glycine powder airpolishing on the gingiva. J Clin Periodontol 35(4):324-332. https://doi.org/10.1111/j.1600-051X.2007.01195.x

33. Abdin H (2007) Bonferroni and Sidak corrections for multiple comparisons. In: Salkind NJ (ed) Encyclopedia of Measurement and Statistics. Sage, Thousand Oaks

34. Petersilka GJ (2011) Subgingival air-polishing in the treatment of periodontal biofilm infections. Periodontol 55(1):124-142. https:// doi.org/10.1111/j.1600-0757.2010.00342.x

35. Louropoulou A, Slot DE, Van der Weijden F (2015) Influence of mechanical instruments on the biocompatibility of titanium dental implants surfaces: a systematic review. Clin Oral Implants Res 26(7):841-850. https://doi.org/10.1111/clr.12365
36. Schmage P, Kahili F, Nergiz I, Scorziello TM, Platzer U, Pfeiffer P (2014) Cleaning effectiveness of implant prophylaxis instruments. Int J Oral Maxillofac Implants 29(2):331-337. https://doi.org/10. $11607 /$ jomi.2524

37. Sammons RL, Lumbikanonda N, Gross M, Cantzler P (2005) Comparison of osteoblast spreading on microstructured dental implant surfaces and cell behaviour in an explant model of osseointegration. A scanning electron microscopic study. Clin Oral Implants Res 16(6):657-666. https://doi.org/10.1111/j.16000501.2005.01168.x

38. Huang YS, Hung CY, Huang HH (2019) Surface changes and bacterial adhesion on implant abutment materials after various clinical cleaning procedures. J Chin Med Assoc 82(8):643-650. https:// doi.org/10.1097/JCMA.0000000000000139

39. Tastepe CS, Lin X, Donnet M, Wismeijer D, Liu Y (2017) Parameters that improve cleaning efficiency of subgingival air polishing on titanium implant surfaces: an in vitro study. $\mathrm{J}$ Periodontol 88(4):407-414. https://doi.org/10.1902/jop.2016. 160270

40. Lasserre JF, Brecx MC, Toma S (2020) Implantoplasty versus glycine air abrasion for the surgical treatment of peri-implantitis: a randomized clinical trial. Int J Oral Maxillofac Implants 35(35): 197-206. https://doi.org/10.11607/jomi.6677

41. Moharrami M, Perrotti V, Iaculli F, Love RM, Quaranta A (2019) Effects of air abrasive decontamination on titanium surfaces: a systematic review of in vitro studies. Clin Implant Dent Relat Res 21(2):398-421. https://doi.org/10.1111/cid.12747

42. Valderrama P, Blansett JA, Gonzalez MG, Cantu MG, Wilson TG (2014) Detoxification of implant surfaces affected by peri-implant disease: an overview of non-surgical methods. Open Dent J 8:7784. https://doi.org/10.2174/1874210601408010077

43. Serino G, Hultin K (2019) Periimplant disease and prosthetic risk indicators: a literature review. Implant Dent 28(2):125-137. https:// doi.org/10.1097/ID.0000000000000841

Publisher's note Springer Nature remains neutral with regard to jurisdictional claims in published maps and institutional affiliations. 